\title{
Non-neoplastic mortality of European workers who produce man made vitreous fibres
}

D Sali, P Boffetta, A Andersen, J W Cherrie, J Chang Claude, J Hansen, J H Olsen, A C Pesatori, N Plato, L Teppo, P Westerholm, P Winter, R Saracci

International Agency for Research on Cancer, Lyon, France D Sali

P Boffetta

R Saracci

Section of Workers Preventive Medicine, University of Pavia, Italy

D Sali

Norwegian Cancer Registry, Oslo, Norway A Andersen

University of Aberdeen and Institute of Occupational

Medicine, United

Kingdom

J W Cherrie

German Center for Cancer Research, Heidelberg, Germany J Chang Claude

Danish Cancer Society, Copenhagen, Denmark

J Hansen

J H Olsen

University of Milan, Italy

A C Pesatori

Karolinska Hospital, Stockholm, Sweden N Plato

Finnish Cancer Registry, Helsinki, Finland

L Teppo

National Institute of Occupational Health, Solna, Sweden

$\mathrm{P}$ Westerholm

MRC Environmental Epidemiology Unit, Southampton, United Kingdom

$\mathrm{P}$ Winter

National Research Council, Pisa, Italy R Saracci

Correspondence to: Dr P Boffetta, International Agency for Research on Cancer, 150 Cours

Albert-Thomas, 69372 Lyon Cedex 08, France. Telephone 0033472738485 ; fax 0033 4 72738342; email:

boffetta@iarc.fr

Accepted 8 March 1999
Abstract

Objective-To study mortality from nonneoplastic diseases among European workers who produce man made vitreous fibres (MMVF).

Methods-11 373 male workers were studied, who were employed for at least 1 year in the production of rock or slag wool (RSW), glass wool (GW), and continuous filament (CF) in 13 factories from seven European countries. Workers were followed up from the beginning of production, between 1933 and 1950 to $1990-2$ and contributed 256352 person-years of observation. Standardised mortality ratios (SMRs) were calculated with national mortalities for reference; an internal exposure-response analyses based on multivariate Poisson regression models was also conducted.

Results-Mortality from bronchitis, emphysema, and asthma was not increased (SMR 1.03, 95\% confidence interval $(95 \%$ CI) 0.82 to 1.28 ). In RSW workers, there was no overall increase in mortality from non-malignant renal diseases (SMR 0.97, $95 \%$ CI 0.36 to 2.11 ), although there was the suggestion of an increase in risk with duration of employment. Mortality from ischaemic heart disease was not increased overall (SMR 1.03, 95\% CI 0.96 to 1.11), but RSW and CF workers with $\geqslant 30$ years since first employment had a higher risk. RSW and CF workers showed an increased mortality from external causes, mainly motor vehicle accidents and suicide, which was higher among workers with a short duration of employment.

Conclusions-Mortality from most nonneoplastic diseases does not seem to be related to employment in the MMVF industry. The results on mortality from ischaemic heart disease and nonmalignant renal diseases, however, warrant further investigations.

(Occup Environ Med 1999;56:612-617)

Keywords: epidemiology; man made vitreous fibres; ischaemic heart disease; respiratory disease; renal disease

Since 1976, the International Agency for Research on Cancer (IARC) has been conducting a cohort study of workers in Europe who produce man made vitreous fibre (MMVF). ${ }^{1}$ The main objective of the study was to assess whether an increased risk of lung cancer or mesothelioma exists among these work- ers. Among the other diseases possibly associated with exposure to MMVF, chronic bronchitis and emphysema are of interest because of the physicochemical similarities between MMVFs and asbestos, and previous reports of an increased risk of bronchitis after inhalation of MMVFs. ${ }^{2} 3$ The risk from nonmalignant renal diseases is also of interest because of the excess of mortality found in a similar cohort in the United States ${ }^{4}$ and because of the possible association between exposure to silica and renal diseases. ${ }^{5}$ We present the results for non-neoplastic causes of death of an update of the follow up of mortality of the European cohort. Results up to 1987 have previously been reported, ${ }^{6}$ as well as detailed results on cancer mortality. ${ }^{1}$

\section{Methods}

The cohort comprises male workers employed for at least 1 year during the period 1933-77 in 13 MMVF factories in Denmark, Finland, Norway, Sweden, the United Kingdom, Germany, and Italy. Seven factories produced rock or slag wool (RSW), five factories glass wool (GW), and two factories continuous filament (CF) (one factory produced both GW and $\mathrm{CF}$ ). The study population is described in detail in previous reports. ${ }^{1}$

Person-years were calculated from 1 year after the date of first employment until the end of follow up (1990-2, depending on the country) or exit (death, emigration, last contact). Time since first employment was divided into four categories $(1-9,10-19,20-29, \geqslant 30$ years). We have no information on employment of workers after 1977; duration of employment up to 1977 was calculated for employment in production activities only, and divided into four categories $(1-4,5-9,10-19, \geqslant 20$ years).

During the period of our study, important technological changes occurred in the production of RSW and GW. Three technological phases were therefore identified in our study: an early phase, present in five RSW and four GW factories, when batch processes with a high degree of manual handling were in use and no dust suppressing agents were used so that a higher exposure to fibres can be presumed; a late phase, present in all but one GW factory, when modern automated processes were introduced, together with the use of oil or resin binders; and an intermediate phase, present in five RSW and two GW plants. ${ }^{7}$ The early phase was therefore likely to be characterised by higher exposures of MMVFs, as well as of other factors such as general inorganic dust, heat, and physical workload. The date of the 
Table 1 Mortality from selected non-neoplastic causes of death

\begin{tabular}{|c|c|c|c|c|}
\hline Cause of deaths $(I C D-10)^{8}$ & $\begin{array}{l}\text { Rock (slag) wool } \\
\text { Obs } \\
\text { SMR } \\
95 \% C I\end{array}$ & $\begin{array}{l}\text { Glass wool } \\
\text { Obs } \\
\text { SMR } \\
95 \% \text { CI }\end{array}$ & $\begin{array}{l}\text { Continuous filament } \\
\text { Obs } \\
\text { SMR } \\
95 \% \text { CI }\end{array}$ & $\begin{array}{l}\text { Total } \\
\text { Obs } \\
\text { SMR } \\
95 \% C I\end{array}$ \\
\hline \multirow[t]{3}{*}{ All causes (A00-Z99) } & 1241 & 1345 & 172 & 2758 \\
\hline & 1.05 & 1.06 & 1.25 & 1.07 \\
\hline & 0.99 to 1.11 & 1.00 to 1.12 & 1.07 to 1.45 & 1.03 to 1.11 \\
\hline \multirow{3}{*}{ Mental disorders (F00-F99) } & 21 & 6 & 0 & 27 \\
\hline & 1.94 & 0.69 & 0 & 1.34 \\
\hline & 1.20 to 2.97 & 0.25 to 1.50 & (0 to 5.80$)$ & 0.88 to 1.95 \\
\hline \multirow[t]{3}{*}{ Diseases of the nervous system (G00-H95) } & 22 & 24 & 2 & 48 \\
\hline & 0.71 & 0.65 & 0.70 & 0.68 \\
\hline & 0.45 to 1.08 & 0.42 to 0.97 & 0.08 to 2.51 & 0.50 to 0.90 \\
\hline \multirow[t]{3}{*}{ Diseases of the circulatory system (I00-I99) } & 519 & 623 & 66 & 1208 \\
\hline & 0.99 & 1.05 & 1.22 & 1.03 \\
\hline & 0.91 to 1.08 & 0.97 to 1.14 & 0.94 to 1.55 & 0.97 to 1.09 \\
\hline \multirow{3}{*}{ Ischaemic heart disease (I20-I25) } & 335 & 427 & 51 & 813 \\
\hline & 0.97 & 1.05 & 1.43 & 1.03 \\
\hline & 0.87 to 1.08 & 0.95 to 1.15 & 1.06 to 1.88 & 0.96 to 1.11 \\
\hline \multirow{3}{*}{ Cerebrovascular disease (I60-I69) } & 91 & 112 & 11 & 214 \\
\hline & 0.95 & 1.05 & 1.21 & 1.01 \\
\hline & 0.77 to 1.17 & 0.86 to 1.26 & 0.60 to 2.16 & 0.88 to 1.16 \\
\hline \multirow[t]{3}{*}{ Diseases of the respiratory system (J00-J99) } & 71 & 127 & 9 & 207 \\
\hline & 0.97 & 1.18 & 1.05 & 1.09 \\
\hline & 0.76 to 1.23 & 0.98 to 1.40 & 0.48 to 2.00 & 0.95 to 1.25 \\
\hline \multirow[t]{3}{*}{ Pneumonia (J12-J18) } & 27 & 52 & 5 & 84 \\
\hline & 1.00 & 1.25 & 2.30 & 1.18 \\
\hline & 0.66 to 1.45 & 0.93 to 1.63 & 0.75 to 5.36 & 0.95 to 1.47 \\
\hline \multirow[t]{3}{*}{ Bronchitis, emphysema, and asthma (J40-J46) } & 33 & 46 & 3 & 82 \\
\hline & 0.96 & 1.12 & 0.70 & 1.03 \\
\hline & 0.66 to 1.35 & 0.82 to 1.49 & 0.14 to 2.03 & 0.82 to 1.28 \\
\hline \multirow{3}{*}{ Diseases of the digestive system (K00-K93) } & 53 & 48 & 14 & 115 \\
\hline & 0.97 & 1.08 & 1.60 & 1.07 \\
\hline & 0.72 to 1.27 & 0.80 to 1.44 & 0.87 to 2.68 & 0.88 to 1.28 \\
\hline \multirow[t]{3}{*}{ Cirrhosis of liver (K74) } & 28 & 15 & 12 & 55 \\
\hline & 1.10 & 0.99 & 2.12 & 1.19 \\
\hline & 0.73 to 1.59 & 0.56 to 1.64 & 1.10 to 3.71 & 0.90 to 1.55 \\
\hline \multirow[t]{3}{*}{ Non-malignant renal diseases (N00-N19; N25-N27) } & 6 & 9 & 1 & 16 \\
\hline & 0.97 & 1.11 & 0.95 & 1.04 \\
\hline & 0.36 to 2.11 & 0.51 to 2.10 & 0.02 to 5.31 & 0.59 to 1.69 \\
\hline \multirow[t]{3}{*}{ External causes (V01-Y98) } & 134 & 89 & 29 & 252 \\
\hline & 1.26 & 1.00 & 1.56 & 1.18 \\
\hline & 1.05 to 1.49 & 0.81 to 1.23 & 1.05 to 2.24 & 1.04 to 1.33 \\
\hline \multirow[t]{3}{*}{ Motor vehicle accidents (V20-V79) } & 28 & 29 & 5 & 62 \\
\hline & 1.28 & 1.18 & 0.70 & 1.16 \\
\hline & 0.85 to 1.86 & 0.79 to 1.70 & 0.23 to 1.63 & 0.89 to 1.48 \\
\hline \multirow{3}{*}{ Suicide (X60-X84) } & 57 & 26 & 4 & 87 \\
\hline & 1.44 & 0.97 & 1.52 & 1.26 \\
\hline & 1.09 to 1.87 & 0.64 to 1.43 & 0.41 to 3.89 & 1.01 to 1.56 \\
\hline
\end{tabular}

beginning of each phase varied among factories: the early phase started between 1937 and 1950, the intermediate phase between 1941 and 1955, and the late phase between 1941 and 1961. Workers were also classified by department of employment: primary production, secondary production, maintenance, other specified job, and unspecified or mixed job.

Trained nosologists abstracted the underlying cause of death from the death certificates, with the exception of Denmark where routine data were used. Causes of death were coded according to the version of the international classification of diseases (ICD) in use at the time of death. In this report, the causes are presented according to the 10th revision of the ICD (ICD-10). ${ }^{8}$ Age, calendar period, country and sex specific national mortality reference data were derived from the Mortality Data Bank of the World Health Organisation and used to compute expected deaths. National mortalities were extrapolated back to the date of starting MMVF production when this date was before the available rates; this extrapolation concerned about $2 \%$ of the total personyears. Standardised mortality ratios (SMRs) were calculated by dividing the number of observed deaths by the number of expected deaths. Ninety five per cent confidence intervals (95\% CIs) based on the Poisson distribu- tion of observed deaths were calculated from the person-years program. ${ }^{9}$

For causes of death suggesting an increased risk on the basis of many events and for non-malignant renal diseases, we also fitted multivariate Poisson regression models to calculate relative risks (RRs) and 95\% CIs. ${ }^{10} \mathrm{~A}$ modified version of an SAS program written by Pearce and Checkoway ${ }^{11}$ was used to stratify data for fitting regression models. All the regression models included age (stratified in 2 year intervals), calendar year (5 year intervals), country, type of production, employment (active, inactive, and unknown when information on employment was not available) and, for RSW and GW, technological phase. For bronchitis, emphysema, asthma, and ischaemic heart disease we also carried out an analysis by job title. All variables were treated categorically. The STATA 5.0 statistical software ${ }^{12}$ was used to fit Poisson regression models.

\section{Results}

During the follow up, 11373 workers (4616 produced RSW, $5275 \mathrm{GW}$, and $1482 \mathrm{CF}$ ) contributed a total of 256352 person-years of observation (107 697 in RSW production, 121949 in GW, and 26706 in CF production). At the end of follow up, $71 \%$ of the workers were alive, $24 \%$ had died, and $5 \%$ had 
Table 2 Relative risks of mortality from bronchitis, emphysema, and asthma according to time since first employment, duration of employment, and technological phase at first employment among rock (slag) wool and glass wool workers

\begin{tabular}{|c|c|c|c|c|c|c|}
\hline & \multicolumn{3}{|c|}{ Rock (slag) wool } & \multicolumn{3}{|c|}{ Glass wool } \\
\hline & Obs & $R R$ & $95 \% C I$ & Obs & $R R$ & $95 \% C I$ \\
\hline \multicolumn{7}{|c|}{ Years since first employment: } \\
\hline 1-19† & 12 & 1 & - & 20 & 1 & - \\
\hline $20-29$ & 10 & 0.9 & 0.3 to 2.6 & 17 & 0.7 & 0.3 to 1.6 \\
\hline$\geqslant 30$ & 11 & 1.8 & 0.7 to 7.0 & 9 & 0.4 & 0.1 to 1.1 \\
\hline Trend $\star$ & & 0.5 & & & 0.08 & \\
\hline \multicolumn{7}{|c|}{ Duration of employment (y): } \\
\hline $1-4 \dagger$ & 16 & 1 & - & 16 & 1 & - \\
\hline $5-9$ & 6 & 0.9 & 0.3 to 2.2 & 14 & 1.6 & 0.7 to 3.3 \\
\hline $10-19$ & 8 & 1.1 & 0.4 to 2.8 & 14 & 1.4 & 0.7 to 3.2 \\
\hline$\geqslant 20$ & 3 & 0.6 & 0.2 to 2.6 & 2 & 0.5 & 0.1 to 2.5 \\
\hline Trend $\star$ & & 0.7 & & & 0.9 & \\
\hline \multicolumn{7}{|c|}{ Technological phase at first employment: } \\
\hline Late† & 25 & 1 & - & 6 & 1 & - \\
\hline Intermediate & 4 & 0.4 & 0.1 to 1.6 & 31 & 3.4 & 0.9 to 13.2 \\
\hline Early & 4 & 0.9 & 0.2 to 3.9 & 9 & 1.8 & 0.4 to 7.7 \\
\hline Trend* & & 0.7 & & & 0.2 & \\
\hline
\end{tabular}

${ }^{\star} \mathrm{p}$ Value test for linear trend. $\dagger$ Reference category.

$\mathrm{RR}=$ relative risk controlled for age, calendar year, country, employment status, time since first employment, duration of employment, and technological phase.

Table 3 Standardised mortality ratios for non-malignant renal diseases according to time since first employment, duration of employment, and technological phase at first employment among rock (slag) wool and glass wool workers

\begin{tabular}{|c|c|c|}
\hline & $\begin{array}{l}\text { Rock (slag) wool } \\
\text { Obs } \\
\text { SMR } \\
95 \% \text { CI }\end{array}$ & $\begin{array}{l}\text { Glass wool } \\
\text { Obs } \\
\text { SMR } \\
95 \% \text { CI }\end{array}$ \\
\hline \multicolumn{3}{|c|}{ Years since first employment: } \\
\hline \multirow{3}{*}{$0-19$} & 2 & 3 \\
\hline & 0.56 & 0.66 \\
\hline & 0.07 to 2.09 & 0.14 to 1.92 \\
\hline \multirow[t]{3}{*}{$20-29$} & 2 & 4 \\
\hline & 1.43 & 2.04 \\
\hline & 0.17 to 5.16 & 0.56 to 5.23 \\
\hline \multirow[t]{3}{*}{$\geqslant 30$} & 2 & 2 \\
\hline & 1.49 & 1.16 \\
\hline & 0.18 to 5.39 & 0.14 to 4.18 \\
\hline Trend ${ }^{\star}$ & 0.3 & 0.4 \\
\hline \multicolumn{3}{|c|}{ Duration of employment: } \\
\hline \multirow[t]{3}{*}{$1-9$} & 2 & 6 \\
\hline & 0.52 & 1.07 \\
\hline & 0.06 to 1.86 & 0.39 to 2.33 \\
\hline \multirow[t]{3}{*}{$10-19$} & 2 & 2 \\
\hline & 1.38 & 1.09 \\
\hline & 0.17 to 4.98 & 0.13 to 3.95 \\
\hline \multirow[t]{3}{*}{$\geqslant 20$} & 2 & 1 \\
\hline & 2.30 & 1.41 \\
\hline & 0.28 to 8.30 & 0.04 to 7.85 \\
\hline Trend $\star$ & 0.1 & 0.7 \\
\hline \multicolumn{3}{|c|}{ Technological phase at first employment: } \\
\hline \multirow{3}{*}{ Late } & 3 & 1 \\
\hline & 0.68 & 0.78 \\
\hline & 0.14 to 2.00 & 0.02 to 4.35 \\
\hline \multirow[t]{3}{*}{ Intermediate } & 1 & 8 \\
\hline & 1.14 & 1.85 \\
\hline & 0.03 to 6.33 & 0.80 to 3.64 \\
\hline \multirow{3}{*}{ Early } & 2 & 0 \\
\hline & 2.17 & 0 \\
\hline & 0.26 to 7.85 & 0 to 1.46 \\
\hline Trend ${ }^{\star}$ & 0.2 & 0.2 \\
\hline
\end{tabular}

${ }^{\star} \mathrm{p}$ Value test for linear trend.

emigrated or were lost to follow up. The percentage of person-years contributed by workers with $\geqslant 20$ years since first employment was $26.4 \%$ (28.7\% in RSW production, $27.8 \%$ in GW, and $10.9 \%$ in CF workers). Workers with $\geqslant 10$ years of employment contributed $20.7 \%$ of person-years $(22.8 \%$ in RSW production, $19.5 \%$ in GW, and $17.4 \%$ in $\mathrm{CF}$ workers).

The number of observed deaths and the SMRs for selected causes of deaths are shown in table 1 . We found a total of 207 deaths from non-neoplastic respiratory diseases, of which 84 were from pneumonia, 82 from bronchitis, emphysema, and asthma, and five from pneumoconiosis including one from asbestosis (from factory 7, GW, Sweden). The SMR analysis showed a slight increase of mortality from respiratory disease in the whole cohort (SMR 1.09, 95\% CI 0.95 to 1.25), which was present in the GW and the CF subcohorts but not in the RSW subcohort. In internal analyses, mortality from bronchitis, emphysema, and asthma (table 2) was slightly higher among RSW workers with $\geqslant 30$ years since first employment than among other RSW workers. A trend in the opposite direction was suggested among GW workers. The analysis according to duration of employment was limited by the few deaths among workers with $\geqslant 20$ years of employment, but did not suggest an exposureresponse relation for either RSW or GW. We did not find any significantly increased risk in the analysis by job title (results not shown in detail).

There were 16 deaths from non-neoplastic renal diseases, of which three were from acute nephritis or acute renal failure, 10 from chronic nephritis or chronic renal failure, and three from renal failure unspecified as acute or chronic. Table 3 presents the SMRs according to time since first employment, duration of employment, and technological phase: although these results are based on small numbers, mortality was somewhat higher among RSW and GW workers with $<20$ years between first employment and death. In an internal analyses of duration of employment, the RRs among RSW workers relative to the workers employed for $1-9$ years were 2.9 (95\% CI 0.3 to 30) for 10-19 years employment and 7.0 (95\% CI 0.4 to 130$)$ for workers employed $\geqslant 20$ years. A similar analysis on technological phase at first employment yielded RRs of 1.0 (late phase, reference category), 1.1 (95\% CI 0.04 to 32, intermediate phase), and 1.6 (95\% CI 0.07 to 34 , early phase).

We found a total of 1208 deaths from cardiovascular diseases, of which 813 were from ischaemic heart disease and 214 were from cerebrovascular accidents. Mortality from ischaemic heart disease was increased among CF workers, but not among RSW or GW workers (table 1). We found a higher mortality among workers from the United Kingdom, both in production of GW (SMR 1.20, 95\% CI 1.06 to $1.35,273$ deaths) and CF (SMR 1.58, $95 \%$ CI 1.13 to $2.14,41$ deaths). However, when we accounted for local variation in mortality from ischaemic heart disease by applying the ratio of local versus national mortalities to the expected deaths, the SMR in the GW subcohort from the United Kingdom was decreased to 1.03 (95\% CI 0.91 to 1.16$)$. Mortality from ischaemic heart disease was decreased in the GW subcohorts from Sweden (SMR $0.85,95 \%$ CI 0.69 to 1.03 ) and Italy (SMR 0.50, 95\% CI 0.20 to 1.02 ). In internal analyses (table 4), RSW and CF workers with $\geqslant 30$ years since first employment had a higher risk than workers with $<30$ years: this pattern was not found among GW workers. The analysis by duration of employment, on the other hand, suggested a decreasing risk among RSW 
Table 4 Relative risks of mortality from ischaemic heart disease according to time since first employment, duration of employment, and technological phase at first employment

\begin{tabular}{|c|c|c|c|}
\hline & $\begin{array}{l}\text { Rock (slag) wool } \\
\text { Obs } \\
\text { RR } \\
95 \% \text { CI }\end{array}$ & $\begin{array}{l}\text { Glass wool } \\
\text { Obs } \\
R R \\
95 \% C I\end{array}$ & $\begin{array}{l}\text { Continuous filament } \\
\text { Obs } \\
R R \\
95 \% \text { CI }\end{array}$ \\
\hline \multicolumn{4}{|c|}{ Years since first employment: } \\
\hline \multirow[t]{3}{*}{$0-9 \dagger$} & 38 & 49 & 10 \\
\hline & 1 & 1 & 1 \\
\hline & - & - & - \\
\hline \multirow[t]{3}{*}{$10-19$} & 84 & 128 & 25 \\
\hline & 0.9 & 1.0 & 0.9 \\
\hline & 0.6 to 1.3 & 0.7 to 1.5 & 0.3 to 2.2 \\
\hline \multirow{3}{*}{$20-29$} & 101 & 122 & 12 \\
\hline & 1.0 & 0.8 & 0.8 \\
\hline & 0.6 to 1.6 & 0.5 to 1.2 & 0.2 to 2.7 \\
\hline \multirow[t]{3}{*}{$\geqslant 30$} & 112 & 128 & 4 \\
\hline & 1.6 & 0.8 & 3.1 \\
\hline & 0.9 to 3.0 & 0.5 to 1.3 & 0.5 to 18.7 \\
\hline Trend ${ }^{\star}$ & 0.05 & 0.2 & 0.7 \\
\hline \multicolumn{4}{|c|}{ Duration of employment (y): } \\
\hline \multirow[t]{3}{*}{$1-4 \dagger$} & 152 & 184 & 12 \\
\hline & 1 & 1 & 1 \\
\hline & - & - & - \\
\hline \multirow[t]{3}{*}{$5-9$} & 67 & 84 & 17 \\
\hline & 1.0 & 0.8 & 1.3 \\
\hline & 0.7 to 1.3 & 0.7 to 1.1 & 0.6 to 2.9 \\
\hline \multirow[t]{3}{*}{$10-19$} & 71 & 99 & 18 \\
\hline & 0.9 & 1.0 & 2.5 \\
\hline & 0.6 to 1.2 & 0.8 to 1.4 & 1.0 to 6.2 \\
\hline \multirow[t]{3}{*}{$\geqslant 20$} & 45 & 60 & 4 \\
\hline & 0.7 & 1.2 & 1.6 \\
\hline & 0.5 to 1.0 & 0.8 to 1.7 & 0.3 to 8.7 \\
\hline Trend ${ }^{\star}$ & 0.07 & 0.5 & 0.1 \\
\hline \multicolumn{4}{|c|}{ Technological phase at first employment: } \\
\hline \multirow[t]{3}{*}{ Late† } & 225 & 88 & - \\
\hline & 1 & 1 & \\
\hline & - & - & \\
\hline \multirow[t]{3}{*}{ Intermediate } & 59 & 222 & - \\
\hline & 1.0 & 1.3 & \\
\hline & 0.7 to 1.4 & 0.9 to 1.9 & \\
\hline \multirow[t]{3}{*}{ Early } & 51 & 117 & - \\
\hline & 1.0 & 1.6 & \\
\hline & 0.7 to 1.5 & 1.0 to 2.5 & \\
\hline Trend ${ }^{\star}$ & 0.9 & 0.04 & \\
\hline
\end{tabular}

${ }^{\star} \mathrm{p}$ Value test for linear trend. †reference category.

$\mathrm{RR}=$ relative risk controlled for age, calendar year, country, employment status, time since first employment, duration of employment, and technological phase.

workers with increasing duration. Results according to the technological phase were unremarkable among RSW workers, whereas GW workers first employed in the early phase had an RR of 1.6 (95\% CI 1.0 to 2.5) compared with workers first employed in the late phase. This trend was stronger among workers of the largest GW factory (factory 10, from the United Kingdom) than among other GW workers: in factory 10 , the RRs were 1.7 (95\% CI 1.1 to 2.7 ) for first employment in the intermediate phase and 2.5 (95\% CI 1.1 to 5.7) for first employment in the early phase. In the whole cohort, the risk of ischaemic heart disease was higher among maintenance workers (SMR 1.18, 95\% CI 1.00 to 1.38 ) than among other workers. No excess of mortality from cerebrovascular accidents was found, according to either type of production, country, or technological phase.

The RSW workers experienced an increased mortality from mental disorders. Among 21 such deaths, eight were from alcoholism, three from alcoholic psychoses, and five from senile dementia or psychosis. No deaths from mental disorders occurred among workers with $>20$ years of employment (1.4 expected). The analysis by country was based on small numbers; however, the highest risk was found in Germany (SMR 2.23, 95\% CI 0.96 to 4.40 , 8 deaths).
In total 115 deaths from diseases of the digestive system were found, of which 55 were from hepatic cirrhosis, 23 from gastrointestinal ulcers, eight from pancreatic diseases, six from chronic enteritis, and three from cholelithiasis. Mortality from cirrhosis of the liver was significantly increased in the CF subcohort, but not among RSW and GW workers (table 1).

Suicide $(\mathrm{n}=83)$, motor vehicle accidents $(n=62)$, injuries of undetermined origin $(n=23)$, and accidental falls $(n=21)$ were the most frequent external causes of death. Mortality from external causes was increased among RSW and CF workers, but not among GW workers (table 1). The risk decreased steadily with duration of employment in the cohort as a whole (RR $0.7,95 \%$ CI 0.5 to 1.0 , for 5-9 years; RR $0.6,95 \%$ CI 0.4 to 1.0 , for $10-19$ years; RR $0.5,95 \%$ CI 0.2 to 1.0 , for $\geqslant 20$ years, with $1-4$ years of employment as the reference category) and in all the three subcohorts. Maintenance workers experienced the highest mortality from external causes (SMR 1.36, 95\% CI 1.01 to 1.79 ).

Mortality from the remaining causes and groups of causes was unremarkable in the whole cohort and in the three subcohorts.

\section{Discussion}

The present study describes the mortality from non-neoplastic causes of a cohort of MMVF workers with $>1$ year of employment. The follow up was successful for a large proportion of the cohort (95\%); however, only the underlying cause of death reported on the death certificate was used in the analysis. This approach is more valid for the study of diseases with high lethality - such as malignant neoplasms - than for chronic diseases with relatively low lethality - such as asthma and chronic renal disease. ${ }^{13}{ }^{14}$ For diseases with low lethality, differences in the accessibility and quality of health care and in the likelihood of having the disease mentioned on the death certificate may be linked to exposure and therefore represent a potential source of differential misclassification. Also, the absence of a direct measure of exposure to MMVFs and other workplace pollutants is a limitation of the study. Only indirect indicators - such as time since first employment, duration of employment, and technological phase at first employment were used to measure exposure. The lack of information on employment after 1977 would have resulted in underestimation of duration of employment, and attenuation of the estimate of the doseresponse according to this variable.

This cohort does not seem to have experienced favourable mortality compared with the underlying population of the corresponding countries (so called healthy worker effect). A possible explanation of this phenomenon is the low skill of most of the workers, which might be associated with high risk lifestyles, as also suggested by the increased mortality from cirrhosis of the liver and suicide (table 1). This effect persisted despite the exclusion of workers with $<1$ year of employment.

The present analysis was mainly focused on mortality from non-neoplastic diseases that 
could be associated with exposures present in the MMVF production environment-such as chronic obstructive pulmonary disease. However, we also examined other diseases for which no association with MMVF production was postulated at the beginning of the study.

Development of chronic obstructive pulmonary disease in workers exposed to MMVFs is a subject for debate. Marsh et $a l^{4}$ found non-significantly increased SMRs from bronchitis, asthma, and emphysema among men in a United States RSW cohort, based on 25 deaths. The previous follow up of the same cohort, including also GW workers for a total of 48 deaths $^{3}$ and an additional Canadian study, ${ }^{15}$ failed to find any excess of mortality from non-malignant respiratory diseases among workers who produced GW. Three cohort studies of workers who produced CF did not find any excess mortality from non-malignant respiratory diseases..$^{316} 17$ In a mortality case-control study carried out in a large GW production plant included in the United States study already mentioned, ${ }^{3}$ the risk of non-malignant respiratory diseases was increased, although not significantly, in the highest categories of exposure to respirable fibres and to respirable silica. ${ }^{18}$ In morbidity studies, Engholm and von Schmalensee found an increased risk of bronchitis in workers exposed to MMVFs compared with those not exposed $^{2}$ after having taken into account smoking and exposure to asbestos, and Hunting and Welch found a more than doubled risk of chronic bronchitis among sheet metal workers other than welders with high exposure to MMVFs. ${ }^{19}$

Neither an overall increase in mortality from bronchitis, emphysema, and asthma nor a consistent trend in risk with time since first employment, duration, or technological phase was evident from the present analysis. Even if mortality from these diseases is higher in this follow up than in the previous one ${ }^{6}$ our data do not support the hypothesis of a causal relation between employment in the production of MMVFs and development of bronchitis, emphysema, and asthma.

We found a suggestion of an increasing risk of death from non-malignant renal diseases among RSW workers with duration of employment or employment in the early technological phase. No such relation was found in the GW subcohort. The few deaths, however, limited the power of our analyses and the precision of the risk estimates. In the previous follow up of this cohort, mortality from this cause was not examined in detail.

A relation between exposure to crystalline silica and renal diseases is well documented. ${ }^{20-23}$ The MMVFs are silicon based compounds which, however, contain no crystalline silica. Marsh et $a l^{\beta}$ also noted an increased mortality from nephritis and nephrosis, with an SMR of $1.46(\mathrm{p}<0.01)$ in the MMVF industry in the United States. The excess was concentrated among RSW workers; an extension of the follow up in this group showed 19 observed and 7.5 expected deaths. ${ }^{4}$ However, there was no apparent trend with either duration of employment or time since first employment. It is unclear whether the mechanisms proposed to explain the nephrotoxic effect of crystalline silica, and in particular the formation of autoantibodies, might operate after exposure to MMVFs. Additional studies, preferably based on morbidity data, are warranted.

Mortality from ischaemic heart disease in our cohort was comparable with that of the general population, as in the previous follow up. An increase in risk was present among GW workers first employed in the early technological phase, ${ }^{6}$ and in RSW and CF workers after 30 years since first employment. The main known occupational risk factors of ischaemic heart disease are heat, carbon monoxide, and physical strain. ${ }^{24-26}$ These factors might explain at least in part our findings, as they might have occurred in the earlier phase of MMVF production. The evidence available from other studies of MMVF workers does not support an aetiological relation between exposure to MMVF and ischaemic heart disease. In the 1985 follow up of a large United States MMVF cohort, the SMR for all heart diseases was not increased. ${ }^{3}$ In the 1989 update of the RSW subcohort, there was no excess in mortality from ischaemic heart disease among male workers; no trend according to time since first employment or duration of employment was present for mortality from cardiovascular diseases as a whole, which consisted mainly of death from ischaemic heart disease. ${ }^{4}$ No excess of deaths due to circulatory diseases was noted among Canadian GW workers ${ }^{15}$; among CF workers a deficit was found in two studies from the United States ${ }^{18}$ and Canada. ${ }^{17}$

The increased mortality from external causes was already noticed in the previous follow up of this cohort. ${ }^{6}$ The inverse relation between risk of death from external causes and duration of employment is similar to that found by Wong et $a l^{27}$ among workers in the reinforced plastics industry, and is present in all three subcohorts. Such a pattern of risk is compatible with extraoccupational factors that are inversely correlated with working stability. We have no information on such factors, although a case-control study of lung cancer is going on in the RSW subcohort, from which a sample of workers will be interviewed about their smoking and alcohol consumption. These data will also contribute to the interpretation of the findings on mortality from external causes.

The study was partially supported by the Joint European Medical Research Board (JEMRB); DS worked on this study under the tenure of an IARC Special Training Award.

1 Boffetta P, Saracci R, Andersen A, et al. Cancer mortality mong man-made vitreous fibre production workers. Epidemiology 1997;8:259-68.

2 Engholm G, von Schmalensee G. Bronchitis and exposure to man-made mineral fibres in non-smoking construction workers. Eur F Respir Dis 1982;118(suppl):73-8.

3 Marsh GM, Enterline PE, Stone RA, et al. Mortality among a cohort of US man-made mineral fiber workers: 1985 follow-up. F Occup Med 1990;32:594-604.

4 Marsh GM, Stone RA, Youk AO, et al. NAIMA mortality surveillance program for the US cohort of fiber glass, rock wool and slag wool workers: mortality patterns among rock wool and and slag wool workers: mortality patterns among rock wool and
slag wool workers - 1989 update. Final report. Pittsburgh, PA: slag wool workers - 1989 update.

5 Goldsmith JR, Goldsmith DF. Fiberglass or silica exposure and increased nephritis or ESRD (end-stage renal disease). Am F Ind Med 1993;23:873-81. 
6 Simonato L, Fletcher AC, Cherrie JW, et al. The International Agency for Research on Cancer historical study of $\mathrm{MMMF}$ production workers in seven European countries: extension of the follow-up. Ann Occup Hyg

7 Dodgson J, Cherrie J, Groat S. Estimates of past exposure to respirable man-made mineral fibres in the European insulation wool industry. Ann Occup Hyg 1987;31:567-82.

8 World Health Organization. International Statistical Classification of Diseases and Related Health Problems, Tenth Revision (ICD-10). Geneva: WHO, 1992.

9 Coleman M, Douglas A, Hermon C, et al. Cohort study analysis with a FORTRAN computer program. Int f Epidemiol 1986;15:134-7.

10 Breslow NE, Day NE. Statistical methods in cancer research. Vol 2. The design and analysis of cohort studies. Lyon: International Agency for Research on Cancer, 1987. (IARC Sci Publ No 82).

11 Pearce N, Checkoway H. A simple computer program for generating person-time data in cohort studies involving generating person-time data in cohort studies involving

12 Stata Corporation. Stata statistical software, release 5.0. College Station, TX: Stata Corporation, 1997.

13 Milham S. Using multiple cause of death coding in occupational mortality studies. Am f Ind Med 1988;14:341-4.

14 Steenland K, Nowlin S, Ryan B, et al. Use of multiple-cause mortality data in epidemiologic analyses: US rate and proportion files developed by the National Institute for Occupational Safety and Health and the National Cancer Institute. Am ₹ Epidemiol 1992;136:855-62.

15 Shannon HS, Jamieson E, Julian JA, et al. Mortality experience of Ontario glass fibre workers: extended follow-up. Ann Occup Hyg 1987;31:657-62.

16 Chiazze L, Watkins DK, Fryar C. Historical cohort mortality study of a continuous filament fiberglass manufacturing plant. f Occup Environ Med 1997;39:43241
17 Shannon HS, Jamieson E, Julian JA, et al. Mortality of glass filament (textile) workers. Br F Ind Med 1990;47:533-6.

18 Chiazze L, Watkins DK, Fryar C, et al. A case-control study of malignant and non-malignant respiratory disease among employees of a fibreglass manufacturing facility, II. Exposure assessment. Br F Ind Med 1993;50:717-25.

19 Hunting KL, Welch LS. Occupational exposure to dust and lung disease among sheet metal workers. $\mathrm{Br} \mathcal{F}$ Ind $\mathrm{Med}$ 1993;50:432-42.

$20 \mathrm{Ng}$ TP, Lee HS, Phoon WH. Further evidence of human silica nephrotoxicity in occupationally exposed workers. $\mathrm{Br}$ f Ind Med 1993;50:907-12.

21 Steenland NK, Thun MJ, Ferguson CW, et al. Occupational and other exposures associated with male end-stage renal disease. Am f Public Health 1990;80:153-7.

22 Steenland K, Brown D. Mortality study of gold miners exposed to silica and non-asbestiform amphibole minerals: an update with 14 more years of follow-up. Am 7 Ind Med 1995;27:217-29.

23 Calvert GM, Steenland K, Palu S. End-stage renal disease among silica-exposed gold miners. $\mathcal{F} A M A$ 1997;277:121923.

24 Wingren G, Englander V. Mortality and cancer morbidity in a cohort of Swedish glassworkers. Int Arch Occup Environ Health 1990;62:253-7.

25 Koskela RS. Cardiovascular diseases among foundry workers exposed to carbon monoxide. Scand 7 Work Environ Health 1994;20:286-93.

26 Wild P, Moulin JJ, Ley FX, et al. Mortality from cardiovascular diseases among potash miners exposed to heat. Epidemiology 1995;6:243-7.

27 Wong O, Trent LS, Whorton MD. An updated cohort mortality study of workers exposed to styrene in the reinforced plastics and composites industry. Occup Environ Med 1994; 51:386-96.

\section{Rejected manuscripts}

From February 1994, authors whose submitted articles are rejected will be advised of the decision and one copy of the article, together with any reviewer's comments, will be returned to them. The fournal will destroy remaining copies of the article but correspondence and reviewers' comments will be kept. 